University of Nebraska - Lincoln

DigitalCommons@University of Nebraska - Lincoln

August 2006

\title{
Assessing the Forecasting Accuracy of Alternative Nominal Exchange Rate Models: The Case of Long Memory
}

David Karemera

South Carolina State University, Orangeburg, South Carolina, USA, karemera@scsu.edu

Benjamin J. C. Kim

University of Nebraska-Lincoln, bkim2@unl.edu

Follow this and additional works at: https://digitalcommons.unl.edu/econfacpub

Part of the Economics Commons

Karemera, David and Kim, Benjamin J. C., "Assessing the Forecasting Accuracy of Alternative Nominal Exchange Rate Models: The Case of Long Memory" (2006). Economics Department Faculty Publications. 29.

https://digitalcommons.unl.edu/econfacpub/29

This Article is brought to you for free and open access by the Economics Department at DigitalCommons@University of Nebraska - Lincoln. It has been accepted for inclusion in Economics Department Faculty Publications by an authorized administrator of DigitalCommons@University of Nebraska - Lincoln. 


\title{
Assessing the Forecasting Accuracy of Alternative Nominal Exchange Rate Models: The Case of Long Memory
}

\author{
David Karemera* and Benjamin J. C. Kim** \\ * Department of Economics, School of Business, South Carolina State University, Orange- \\ burg, South Carolina, USA (Corresponding author, email karemera@scsu.edu) \\ ** Department of Economics, College of Business Administration, University of $\mathrm{Ne}-$ \\ braska-Lincoln, Lincoln, Nebraska, USA
}

\begin{abstract}
This paper presents an autoregressive fractionally integrated moving-average (ARFIMA) model of nominal exchange rates and compares its forecasting capability with the monetary structural models and the random walk model. Monthly observations are used for Canada, France, Germany, Italy, Japan, and the United Kingdom for the period of April 1973 through December 1998. The estimation method is Sowell's (1992) exact maximum likelihood estimation. The forecasting accuracy of the long-memory model is formally compared to the random walk and the monetary models, using the recently developed Harvey, Leybourne, and Newbold (1997) test statistics. The results show that the longmemory model is more efficient than the random walk model in steps-ahead forecasts beyond 1 month for most currencies and more efficient than the monetary models in multistep-ahead forecasts. This new finding strongly suggests that the long-memory model of nominal exchange rates be studied as a viable alternative to the conventional models.

Keywords: fractional integration; forecasting; foreign exchange rate
\end{abstract}

\section{Introduction}

Foreign exchange rates have been intensively studied since major industrial countries switched to the floating exchange rate system in the early 1970s. Numerous studies have been conducted on the determination and the statistical behavior of the exchange rate. Time series properties of the exchange rate are crucial in understanding the models of exchange rate determination and the forecasting performance of those models. This proliferation of studies has been in part aided by the availability of rich data sets of different collection intervals (i.e., daily, weekly and monthly) and by recent development of econometric methodologies. Much of the model building is based on the monetary approach to exchange rates, in which the exchange rate is treated as a price of one currency in terms of another. 
The monetary models of exchange rate determination have gone through a vast amount of scrutiny in forecasting and efficiency tests. These models provided fairly good forecasting results in the early years of the floating rate system, but their forecasting accuracy has deteriorated markedly from the 1980s. The reduced-form equations of the model yielded coefficient estimates that were both imprecise and statistically insignificant. This is best demonstrated in the results of Meese and Rogoff (1983a), who showed that the performance of the monetary models was inferior to a simple random walk model of exchange rates. ${ }^{1}$

The poor forecasting performance of the structural models has been attributed to many factors. First, exchange rates may diverge from the levels dictated by economic fundamentals due to "rational bubbles" (see, Meese, 1986, and West 1987). Second, Frankel and Froot (1990) and Taylor and Allen (1992) argue, using survey responses, that while the dealers in the foreign exchange market rely more on the economic fundamentals in the long run, they rely more heavily on charts and trends in forming expectations in the short run. Using an error correction model, Kim and Mo (1995), for example, show that, while the random walk model outperforms the monetary structural model in short-run forecasting, the latter outperforms the former in the long run, lending support to the arguments made by Frankel and Froot (1990) and Taylor and Allen (1992).

In this paper, we introduce yet another model of exchange rates for forecasting, i.e., the long-memory model, and compare the forecasting performance of this model with that of monetary models and the random walk model. We first investigate the time series dynamics of nominal exchange rates using the fractionally integrated autoregressive moving average (ARFIMA) model. The long-memory process was first applied to economic time series by Granger (1980), Granger and Joyeux (1980), and Hosking (1981). ${ }^{2}$ It generalizes the traditional autoregressive integrated moving average (ARIMA), by allowing the differencing parameter to take non-integer real values.

Since a long memory in the foreign exchange rate was first suggested by Booth et al. (1982), there have been several applications of the ARFIMA model to foreign exchange rates. Cheung (1993, pp. 93101), using weekly spot exchange rates of five currencies, finds evidence of the presence of long memory and estimates the ARFIMA models using time-domain and frequency-domain maximum likelihood methods. ${ }^{3}$ In a comparison of relative magnitudes of forecast statistics, he finds no difference between the forecasting accuracy of ARFIMA models and that of random walks.

This study extends Cheung's (1993) analysis of the forecasting accuracy of the ARFIMA model by providing a statistical comparison with not only the random walk model but also with a set of monetary structural models. This is a significant extension along the lines of Meese and Rogoff's (1983a) analysis, as we add a different class of models for comparison, i.e., the ARFIMA model, whose concept was barely available at the time of their study. We also employ Sowell's (1992) recursive exact maximum likelihood estimation method, which is shown to be superior to the Fox and Taqqu (1986) method used by Cheung (1993).

1 This well-publicized result was, however, challenged by Wolff (1987). He argued, using a recursive Kalman filter model for forecasting, that the structural monetary models compare favorably with the random walk model for the dollar/DM exchange rate. Schinasi and Swamy (1989) reported similar results.

2 Recent applications of this model include aggregate output (Diebold and Rudebusch, 1989), monetary aggregates (Porter-Hudak, 1990), consumption smoothness (Diebold and Rudebusch, 1991a), foreign exchange rates (Cheung, 1993), purchasing power parity (Cheung and Lai, 1993), forward premium (Baille and Bollerslev, 1994), inflation rates (Hassler and Wolters, 1995), stock prices (Lo, 1991, Cheung and Lai, 1995, 2001), consumption and income (Gil-Alana and Robinson, 2001), to list a few.

3 We thank Fallaw Sowell for additional insight on the difference between Cheung (1993) and Sowell (1992) techniques. 
This paper is organized as follows: the next section presents a brief description of the monetary models and a random walk model. The third section explains a long-memory model of exchange rates and the estimation procedures of the ARFIMA model. The fourth section presents the empirical estimation of these models and comparisons of their forecasting performances. The fifth section concludes the paper with a summary and conclusions.

\section{Traditional Models of Exchange Rates}

\section{The Monetary Models}

Early studies of exchange rate determination were largely based on monetary models. In this paper, we consider three such models: (i) the "flexible-price"' model of Frenkel (1976) and Bilson (1978); (ii) the "sticky-price" model of Dornbusch (1976) and Frankel (1979); and (iii) the "stickyprice/current-account" model of Hooper and Morton (1982). Meese and Rogoff (1983a) compared the forecasting performance of the above three models with that of the random walk for dollar/DM, dollar/ pound, dollar/yen, and the trade-weighted dollar exchange rates, using data for the period March 1973 through June 1981. Their results showed that the random walk model outperformed the three structural monetary models in out-of-sample forecasts.

A general form of the monetary models of exchange rate determination can be written as follows:

$$
\begin{aligned}
S_{t}=\alpha_{0}+\alpha_{1}\left(m_{t}-m_{t}^{*}\right)+\alpha_{2}\left(i_{t}^{\mathrm{ST}}-i_{t}^{\mathrm{ST} *}\right)+\alpha_{3}\left(i_{t}^{\mathrm{LT}}-i_{t}^{\mathrm{LT} *}\right)+\alpha_{4}\left(w_{t}-w_{t}^{*}\right) \\
+\alpha_{5}\left(\mathrm{CTB}_{t}-\mathrm{CTB}_{t}^{*}\right)+\alpha_{6}\left(y_{t}-y_{t}^{*}\right)+\varepsilon_{t}
\end{aligned}
$$

where $S_{t}$ is the $\log$ of the spot exchange rate, $m_{t}$ is the log of money supply, $i_{t}^{\text {ST }}$ is the level of shortterm interest rate, $i_{t}^{\mathrm{LT}}$ is the level of the long-term interest rate, $w_{t}$ is the log of real wealth, $\mathrm{CTB}_{t}$ is the cumulated trade balance, and $y_{t}$ is the log of real income. The asterisk denotes the foreign country variable.

The various structural monetary models of exchange rates can be classified by imposing certain restrictions on coefficients:

Frenkel-Bilson model:

$$
\alpha_{1}=1, \alpha_{0} \mathrm{a} 2>0, \alpha_{3}=\alpha_{4}=\alpha_{5}=0, \alpha_{6}<0
$$

Dornbusch-Frankel model:

$$
\alpha_{1}=1, \alpha_{2}<0, \alpha_{3}>0, \alpha_{4}=\alpha_{5}=0, \alpha_{6}<0
$$

Hooper and Morton model:

$$
\alpha_{1}=1, \alpha_{2}<0, \alpha_{3}>0, \alpha_{4}=0, \alpha_{5}<0, \alpha_{6}<0
$$

In this paper, the forecasting performance will be compared among the three monetary exchange rate models, the random walk model, and the long-memory model. This will be done by statistically comparing the multi-step-ahead forecast performance of these models. 


\section{The random walk model}

The general form of the random walk model for exchange rates is written as

$$
S_{t}=S_{t-1}+c+v_{t}
$$

where $c$ is a drift term and $v_{t}$ is a white-noise error term.

\section{The Long-Memory Model of the Foreign Exchange Rates}

The parameter estimates in any regression equation are sensitive to the class of models considered and may be misleading when the model is misspecified. While the issue of model misspecification is hardly settled conclusively, employing a larger class of models will certainly help with the accuracy of the inferences drawn from the parameter estimates. The ARFIMA model is a larger class of stochastic processes, of which random walks are special cases. In this vein, the use of the ARFIMA model is preferred to the conventional ARIMA model in modeling the long-run behavior of a macro time series.

Many previous studies have shown that foreign exchange rates exhibit high persistence and behave like a martingale. Standard unit root tests such as the augmented Dickey-Fuller test and the Phillips-Perron test cannot reject the null hypothesis that there is a unit root in exchange rates (see, for example, Meese and Singleton, 1982). However, the ARFIMA model is preferred to the standard unit root model, as it has been shown that the unit root tests have low power against the ARFIMA alternatives (see Diebold and Rudebusch, 1991b, and Sowell, 1992).

A foreign exchange rate, $S_{t}$ follows an $\operatorname{ARFIMA}(p, d, q)$ process if

$$
\Phi(L)(1-L)^{d} S_{t}=\Theta(L) \varepsilon_{t}
$$

where $\Phi(L)=1+\varphi_{1} L+\varphi_{2} L^{2}+\ldots \varphi_{p} L^{p}$ is an autoregressive polynomial and $\Phi(L)=1-\theta_{1} L-\theta_{2} L^{2}$ -... $\theta_{q} L^{q}$ is a moving average polynomial, and

$$
(1-L)^{d}=\sum_{K=0}^{\infty} \frac{\Gamma(k-d) L^{k}}{\Gamma(k+1) \Gamma(-d)}
$$

is the fractional differencing operator and $\Gamma($.$) is the usual gamma function. The roots of \Phi(L)$ and $\Theta(L)$ are assumed to be outside the unit circle. The parameter " $d$ " is known as the memory parameter and is allowed to take any fractional values (fractional integration).

The stochastic process $S_{t}$ is both invertible and stationary if all roots of $\Phi(L)$ and $\Theta(L)$ lie outside the unit circle and $|d|<0.5$. If $d>0.5$, the process is not stationary, because it exhibits an infinite variance (Granger and Joyeux, 1980; Sowell, 1992; Cheung, 1993). Hosking (1981) showed that, for $d \in(0$, $0.5)$, the autocorrelation function for the ARFIMA process, $\gamma(k)=E\left(Z_{t} Z_{t-k}\right)$, satisfies the condition that, as $k \rightarrow \infty, r(k) \sim k^{2 d-1}$. This slow hyperbolic decline is characteristic of ARFIMA processes and contrasts with the faster geometric decay inherent in stationary ARMA models. Therefore, long-memory or long-range dependency between observations widely separated in time can be examined by fractional integration. If $0<d<0.5, \sum_{\mathrm{K}=0}^{\infty} r(k)$ diverges as $k \rightarrow \infty$ and the stochastic processes exhibit 
long-memory or long-range dependency between distant observations. For $d \in(-0.5,0)$, the processes are said to exhibit intermediate or negative long-range dependency. For $d=0$, the processes exhibit short-memory characteristics of stationary ARMA models.

The increased evidence of fractional integration in macroeconomic variables has generated new interest and a host of new techniques for estimating ARFIMA models (see, for example, Diebold and Rudebusch, 1989, 1991a; Cheung and Lai, 2001; and Gil-Alana and Robinson, 2001). Sowell (1992) provides an excellent survey of past estimation methods along with benefits and problems associated with each method. In a rather complex procedure, Sowell outlines a recursive maximum likelihood method for a joint estimation of ARFIMA model parameters. He provides comparative evidence and shows the superior efficiency of his method. For example, in a simulation exercise, Sowell (1992, p. 180) argues, "Generally, the maximum likelihood estimator was superior to the procedures presented in Fox and Taqqu (1986) and in Geweke-Porter-Hudak." The efficiency gains from Sowell's method arise from the use of the interchange integral and the recursive nature of the procedures as described on p. 175. Thus, to our knowledge, this paper is the first to use Sowell's (1992) method to assess the forecasting accuracy of alternative models of nominal exchange rates. Our results extend findings in Cheung (1993) and provide additional insights on alternative estimation and forecasting methodologies. The recursive maximum likelihood procedure is, therefore, used here and is briefly described below.

\section{The exact joint maximum likelihood method}

The long-memory aspect in the nominal exchange rate is captured by estimating the fractionally integrated ARIMA models. The earliest study by Geweke-Porter-Hudak (1983), which is a two-step semi-parametric estimation process, has been demonstrated to have a larger bias and mean squared error than the maximum likelihood estimation method (see Sowell, 1992; Robinson, 1994; and Smith et al., 1997). Therefore, we estimate the ARFIMA model using Sowell's (1992) method of a joint estimation of the time series model parameters. ${ }^{4}$

Consider a normal distribution for the fractionally integrated time series $S_{t^{\prime}}$ generated by the process expressed in equation (3). Assume further that a sample of size $T$ observations is available such that $S_{t}=\left(S_{1}, S_{2}, \ldots, S_{T}\right)$ and $S_{t} \sim N(0, \Sigma)$, where $\Sigma$ is a $T \times T$ covariance matrix. The normal probability density function is given by the following expression:

$$
f\left(S_{t}, \Sigma\right)=(2 \pi)^{-T / 2}|\Sigma|^{-1 / 2} \exp \left\{-\frac{1}{2} S_{t}^{\prime} \Sigma^{-1} S_{t}\right\}
$$

A detailed derivation of equation (5) is available in Sowell (1992). The joint estimation of the model parameters requires the specification and estimation of the covariance matrix in (5) above. Sowell noted that $\Sigma=[\gamma(i-j)]$ for $i, j=1,2, \ldots, T$, and wrote the autocorrelation function in terms of model parameters and then derived the autocovariance function as

$$
\gamma(k)=\frac{1}{2 \pi} \int_{0}^{2 \pi} f_{s}(\lambda) e^{i \lambda k} d \lambda
$$

4 Sowell's (1992) estimation method has so far not been employed in the literature. 
From a given set of parameter values, the maximization routine involves the evaluation of the likelihood function for a global maximum. The spectral density of $S_{t}$ is used in the specification of the autocovariance function and can be derived using the spectral density of $U_{t}=(1-L)^{\mathrm{d}} S_{t}$. Details on the derivation of the ML function and the recursive algorithm are available in Sowell (1992).

In the empirical implementation of the above recursive procedure, the maximization of the likelihood function was performed using a Fortran program provided by Fallaw Sowell and made available at his website. The program estimates ARFIMA $(p, d, q)$ with 16 specifications corresponding to three AR and MA parameters. The Fortran subroutine calls the Davidon Fletcher Powell (DPF) algorithm, which is available in the GQOPT package obtained from Richard Quandt of Princeton University. Starting values were generated by using the GPH spectral regression procedure suggested by Sowell (1992). Several other initial parameter values were tried to ensure that a global maximum was reached. The Akaike information criterion (AIC) and the Schwartz information criterion (SIC) were used in the final model selections (Diebold et al., 1991; Sowell, 1992; and Cheung, 1993). Both criteria were generally consistent in the selections. The results are presented below.

\section{Empirical Results}

In this section, we investigate the forecasting performance of the monetary structural models, the random walk model, and the ARFIMA model of nominal exchange rates for the G-7 countries. ${ }^{5}$ The G-7 countries are Canada, France, Germany, Italy, Japan, and the UK. The time period studied is April 1973 through December 1998 for all countries, except France and Italy owing to data availability. France's time period is from December 1977 through December 1998, while Italy's is from December 1974 through December 1998.

\section{The data}

The monthly data were taken from the IFS CD-ROM. The monetary aggregates are all M1, except M2 for Italy and M0 for the UK. The income measures are the seasonally adjusted industrial production and prices are the consumer price indexes for all countries. Short-term interest rates are Treasurybill rates for Canada, France, Germany, UK, and USA, and the call money rates for Germany, Italy, and Japan. Long-term interest rates are the government bond yields for all countries. Trade balance is the difference between exports and imports for all countries.

\section{Test of long memory in exchange rates}

We report in Table I the results of Sowell's test for long memory in the first-differenced exchange rate series for six currencies, which are defined as the units of national currencies per US dollar. ${ }^{6}$ The table also reports the parameter estimates of the fractionally integrated ARMA models. The estimate of the fractional integration parameter, $d$, is given in the first column. All estimates have the expected

5 No previous study has compared the forecasting efficiency among the ARFIMA models, the monetary structural models, and the random walk model. Cheung (1993) compared the forecasting efficiency between the ARFIMA and random walk models without a statistical test. The well-publicized Meese and Rogoff (1983a, b) studies compared forecasting efficiency between the monetary models and the random walk model.

6 We also estimated $d$ using the two-stage Geweke-Porter-Hudak (1983) method. Three of the six estimates based on the value $T^{1 / 2}$ were very different from those obtained using the exact maximum likelihood method, while fewer estimates were statistically significant. The estimated results may be obtained from the authors upon request. 
Table I. Sowell's joint maximum likelihood estimation of ARFIMA model.

\begin{tabular}{|c|c|c|c|c|c|c|c|}
\hline \multirow[t]{2}{*}{ Currency } & \multirow{2}{*}{$\begin{array}{c}\text { Memory } \\
\text { parameter } \\
d\end{array}$} & \multicolumn{3}{|c|}{ Autoregressive parameters } & \multicolumn{3}{|c|}{ Moving average parameters } \\
\hline & & $\varphi_{1}$ & $\varphi_{2}$ & $\varphi_{3}$ & $\theta_{1}$ & $\theta_{2}$ & $\theta_{3}$ \\
\hline $\mathrm{CD}$ & $\begin{array}{l}0.1562^{* * *} \\
(4.63)\end{array}$ & $\begin{array}{l}-0.1967^{* * *} \\
(8.16)\end{array}$ & $\begin{array}{l}0.1498^{* * *} \\
(4.01)\end{array}$ & $\begin{array}{l}-0.3069 \\
(1.47)\end{array}$ & $\begin{array}{l}-0.2238 \\
(9.49)\end{array}$ & $\begin{array}{l}0.1927^{* * *} \\
(4.73)\end{array}$ & $\begin{array}{l}-0.5502^{* *} \\
(2.51)\end{array}$ \\
\hline $\mathrm{FF}$ & $\begin{array}{l}0.1459^{* *} \\
(1.95)\end{array}$ & $\begin{array}{c}0.113 \\
(1.21)\end{array}$ & $\begin{array}{l}0.1907^{* *} \\
(2.10)\end{array}$ & & $\begin{array}{l}0.9777^{* * *} \\
(39.0)\end{array}$ & & \\
\hline $\mathrm{DM}$ & $\begin{array}{l}0.0679^{*} \\
(1.73)\end{array}$ & $\begin{array}{l}0.1725^{* * *} \\
(4.47)\end{array}$ & $\begin{array}{l}-0.749^{\star * *} \\
(7.08)\end{array}$ & & $\begin{array}{l}-0.525^{* * *} \\
(7.14)\end{array}$ & $\begin{array}{l}0.167^{* *} \\
(2.44)\end{array}$ & \\
\hline IL & $\begin{array}{l}0.1143^{*} \\
(1.91)\end{array}$ & $\begin{array}{l}0.0337^{* * *} \\
(4.65)\end{array}$ & & & & & \\
\hline JY & $\begin{array}{l}0.0797^{* *} \\
(2.07)\end{array}$ & $\begin{array}{l}0.1415^{* * *} \\
(15.5)\end{array}$ & $\begin{array}{l}-0.450^{* * *} \\
(5.61)\end{array}$ & & $\begin{array}{l}-0.456^{* * *} \\
(4.16)\end{array}$ & $\begin{array}{c}0.068 \\
(1.05)\end{array}$ & \\
\hline $\mathrm{BP}$ & $\begin{array}{c}0.009 \\
(0.09)\end{array}$ & $\begin{array}{l}-0.8976 \\
(0.90)\end{array}$ & $\begin{array}{l}-0.0096 \\
(0.09)\end{array}$ & $\begin{array}{c}0.9917 \\
(0.99)\end{array}$ & & & \\
\hline
\end{tabular}

Notes:

1. CD, Canadian dollar; FF, French franc; DM, German mark; IL, Italian lira; JY, Japanese yen; BP, British pound. All exchange rates are foreign currency unit per US dollar.

2. Asymptotic $t$-values in absolute values are in parentheses.

3. Memory parameter $d$ is significant at $5 \%$ or better in the one-tailed test.

*Significance at $10 \%$ level; **significance at $5 \%$ level; ${ }^{* * *}$ significance at $1 \%$ level in two-tailed test.

sign and magnitude consistent with the existence of long memory. Except for the British pound, the estimates are statistically significant and show strong memory at the 5\% level or higher. We used these models to generate the out-of-sample forecasts below.

Most estimates of the autoregressive and moving average parameters are statistically significant at the $5 \%$ level. The French franc exchange rate structure is characterized by a second-order autoregressive and first-order moving average, whereas the German mark and Japanese yen are characterized by second-order autoregressive and moving averages. The Canadian dollar is shown to have a thirdorder autoregressive and moving average. The Italian lira is best specified by a first-order autoregressive structure. The British pound is characterized by insignificant autoregressive parameters and no moving average term. Furthermore, the British pound is the sole currency with a weak or insignificant memory parameter estimate. The L'jung Box statistics, used to test for autocorrelation, all indicate rejection of the null hypothesis of no serial correlation in the exchange rate series examined.

\section{Comparison of Forecast Accuracy: Test of Equality of Forecast Errors}

We now compare the performance of the monetary, random walk, and long-memory models. The three monetary models are estimated using equation (1), with proper parameter restrictions imposed for each model. The estimation results are not reported here to conserve space. These estimated models are used to generate the out-of-sample forecasts and the statistics for forecast errors.

The out-of-sample forecasts are obtained as follows: First, we estimated a regression equation for each of the three monetary models and the random walk model for the period 1974:1-1996:12 (1978:21996:12 for France and 1975:2-1996:12 for Italy because of data availability) and then forecasts are generated by a rolling regression, which updates the parameter coefficients as each additional observation is added. Out of-sample forecast errors are generated for the period 1997:1-1998:12. Secondly, 
the ARFIMA model parameters, which are estimated for the same sample estimation period, are used to generate the out-of-sample forecast errors for the ARFIMA models during the same evaluation period. Thus, for all models, the out-of-sample forecasts are made for 1, 2, 3, 6, 9, and 12 steps-ahead forecasts for the period 1997:1-1998:12.7 The relative forecast efficiency of alternative exchange rate models is evaluated by use of a statistical method proposed by Harvey et al. (1997).

\section{The Harvey, Leybourne, and Newbold test statistic}

In this section, we use a methodology developed by Harvey et al. (1997) (HLN hereafter) to compare the forecasting accuracy of the three groups of exchange rate models. The methodology is briefly described as follows.

Consider that the $h$-step-ahead forecast from the ARFIMA model has produced forecast errors $e_{i t^{\prime}}$ while that from the random walk (or monetary) model has produced forecast errors $e_{2 t}$ for $t=1,2 \ldots$, $n$. Following HLN, the forecast accuracy may be judged by a forecast error function $g\left(e_{t}\right)$. Define $\delta_{t}=$ $g\left(e_{1 t}\right)-g\left(e_{2 t}\right)$ as the difference between the two forecast error functions. The null hypothesis of equal expected forecast errors is $E\left[g\left(e_{1 t}\right)-g\left(e_{2 t}\right)\right]=0$. We write the mean difference as

$$
\bar{\delta}=n^{-1} \Sigma \delta_{t}
$$

where $\delta_{t}=g\left(e_{1 t}\right)-g\left(e_{2 t}\right)$. The HLN test assumes that the $h$-step-ahead forecast is autocorrelated up to lag $h$ and all autocorrelation or order $h$ or higher are zero. ${ }^{8}$ The variance of $\bar{\delta}$ is then computed as

$$
V(\bar{\delta}) \approx n^{-1}\left[\gamma_{0}+2 \sum_{k=1}^{h-1} \gamma_{k}\right]
$$

where $\gamma_{k}$ is the $k$ th autocovariance of $\delta_{t}$. This autocovariance can be estimated by

$$
\hat{\gamma}_{k}=n^{-1} \sum_{t=k+1}^{n}\left(\delta_{t}-\bar{\delta}\right)\left(\delta_{t-k}-\bar{\delta}\right)
$$

The Diebold-Mariano test statistic is then

$$
S_{l}=[\hat{V}(\bar{\delta})]^{-1 / 2} \bar{\delta}
$$

where $\hat{V}(\bar{\delta})$ is obtained by substituting the estimates in (9) into (8). After several approximations and a little algebra, HLN use an unbiased estimator of $\bar{\delta}$ to derive a modified Diebold-Marino estimator:

$$
S_{l}^{*}=\left[\frac{n+1-2 h+n^{-1} h(h-1)}{n}\right]^{-1 / 2} S_{l}
$$

7 For the HLN statistics of Table 2, we have generated statistics for all 12 steps. However, we report the results only for steps, 1 , $2,3,6,9$, and 12 to conserve space. Results for all steps are obtainable from the authors upon request.

8 David Harvey provided insights, in his correspondence with us, on the selection and use of the parameter $h$. The value of $h$ is based on the assumed autocorrelation of lag length $h-1$. He recommends using $h$ equal to the forecast horizon. He also commented on the evidence of the relative efficiency of the HLN statistic. We are thankful to him for his help. 
The statistic in (11), known as the HLN test statistic, is compared to the critical values of the Student $t$ distribution with $n$ degrees of freedom. It has some desirable properties. HLN (1997, p. 293) show that the statistic does not rely on the assumption of unbiased forecasts since an approximately unbiased variance of difference of forecast errors, $\delta_{t^{\prime}}$ was used in the statistical derivation. Furthermore, in simulation experiments using $h=1$ to 10 and sample sizes ranging from $n=8$ to 526 , the HLN statistic is shown to outperform the Diebold-Mariano statistic and is applicable beyond onestep-ahead forecast (HLN 1997, p. 285).

In addition, according to HLN (1997), the modifications to the Diebold-Mariano statistics do not add extra computational costs, while they prove a valuable tool in testing the equality of forecast performance. The modifications correct the test oversize problem inherent in the original Diebold-Mariano statistic. The HLN statistic can be applied to any error function, not necessarily a quadratic loss function.

Finally, HLN (1997) note that their statistic is a modified Diebold-Mariano statistic that "constitutes the best available approach to assessing the significance of observed differences between the performance of two forecasts" (HLN 1997, p. 291). Thus, we use the HLN statistic and the results are discussed below.

\section{The Harvey, Leybourne, and Newbold test results}

Table II presents the HLN test results. The HLN test statistics indicate that the ARFIMA model significantly outperforms the random walk model in all forecast steps beyond 2 months, while the long-memory models are more efficient than the monetary models in all multi-step-ahead forecasts for most countries included in the study. In other words, the HLN statistics indicate, at the 5\% level, that the forecast mean square errors from ARFIMA models are significantly smaller than those from random walk models. This finding is consistent for most countries beyond the 2-months-ahead forecasts.

Similarly, the HLN statistics show, at the 5\% level, that the forecast mean squared errors from ARFIMA models are significantly smaller than those from monetary models, beyond the 1-monthahead forecasts in most countries. For all exchange rates analyzed, the superior performance of ARFIMA models becomes more evident as forecast steps lengthen. The HLN test statistics show significant differences between the two forecast error functions at longer horizons. Thus, the long-memory model becomes convincingly superior in the forecasting accuracy at longer forecast steps.

\section{Summary and Conclusions}

In this paper, we evaluated the forecasting performance of nominal exchange rates using the fractionally integrated ARMA model as an extension of previous studies. We employed Sowell's exact maximum likelihood estimation method and compared the forecasting performance of the ARFIMA model with that of the three monetary structural models and the random walk model with a drift. While structural and random walk models have been amply compared in the past (see Meese and Rogoff, 1983a,b), no comparison has yet been made between monetary and ARFIMA models. Cheung (1993) did not compare the forecasting accuracy of ARFIMA models with the monetary structural models. He did not offer a formal statistical comparison of the forecasting accuracy either, when comparing the ARFIMA models with the random walk models.

Our findings indicate that the ARFIMA model outperforms structural monetary models in shortrun forecasting. Further, the ARFIMA model is also shown to outperform the random walk model 
Table II. The HLN test of equality of forecast performance: comparison of equality of forecast mean square errors for pairs of models by currency and forecast steps.

\begin{tabular}{|c|c|c|c|c|c|c|c|}
\hline Models & $\begin{array}{l}\text { Steps ahead } \\
\text { forecasts }\end{array}$ & $\mathrm{CD}$ & $\mathrm{FF}$ & GM & IL & JY & $\mathrm{BP}$ \\
\hline \multirow[t]{6}{*}{ LM v RW } & 1 step & 0.9119 & 1.8900 & 1.1966 & 2.1108 & 1.2438 & 1.7737 \\
\hline & 2 step & 1.5350 & 3.1810 & 2.0142 & 3.5530 & 2.0936 & 2.9855 \\
\hline & 3 step & 1.9345 & 4.0090 & 2.5384 & 4.4777 & 2.6385 & 3.7625 \\
\hline & 6 step & 2.6587 & 5.5097 & 3.4887 & 6.1540 & 3.6263 & 5.1710 \\
\hline & 9 step & 3.0245 & 6.2677 & 3.9687 & 7.0008 & 4.1252 & 5.8825 \\
\hline & 12 step & 3.1590 & 6.5464 & 4.1451 & 7.3121 & 4.3087 & 6.1441 \\
\hline \multirow[t]{6}{*}{ LM v B-F } & 1 step & 1.2718 & 1.2509 & 1.1850 & 1.6450 & 1.1686 & 1.6139 \\
\hline & 2 step & 2.1408 & 2.1056 & 1.9946 & 2.7689 & 1.9771 & 2.7167 \\
\hline & 3 step & 2.6979 & 2.6535 & 2.5137 & 3.4896 & 2.4791 & 3.4237 \\
\hline & 6 step & 3.7079 & 3.6469 & 3.4547 & 4.7959 & 3.4071 & 4.7054 \\
\hline & 9 step & 4.2181 & 4.1487 & 3.9301 & 5.4558 & 3.8759 & 5.3528 \\
\hline & 12 step & 4.4056 & 4.3332 & 4.1048 & 5.6984 & 4.0483 & 5.5908 \\
\hline \multirow[t]{6}{*}{ LM v F-D } & 1 step & 1.4109 & 3.6838 & 1.1112 & 3.8058 & 1.2750 & 1.8691 \\
\hline & 2 step & 2.3749 & 6.2008 & 1.8705 & 6.4060 & 2.1461 & 3.1462 \\
\hline & 3 step & 2.9930 & 7.8145 & 2.3573 & 8.0732 & 2.7046 & 3.9650 \\
\hline & 6 step & 4.1135 & 10.7400 & 3.2398 & 11.0956 & 3.7172 & 5.4494 \\
\hline & 9 step & 4.6795 & 12.2178 & 3.6855 & 12.6223 & 4.2286 & 6.1992 \\
\hline & 12 step & 4.8875 & 12.7611 & 3.8494 & 13.1835 & 4.4167 & 6.4748 \\
\hline \multirow[t]{6}{*}{ LM v H-M } & 1 step & 1.7319 & 0.8712 & 0.8273 & 0.9176 & 0.9002 & 1.2764 \\
\hline & 2 step & 2.9152 & 1.4665 & 1.3926 & 1.5445 & 1.5153 & 2.1485 \\
\hline & 3 step & 3.6739 & 1.8482 & 1.7550 & 1.9465 & 1.9097 & 2.7077 \\
\hline & 6 step & 5.0492 & 2.5400 & 2.4120 & 2.6752 & 2.6246 & 3.7213 \\
\hline & 9 step & 5.7440 & 2.8895 & 2.7439 & 3.0433 & 2.9857 & 4.2333 \\
\hline & 12 step & 5.9994 & 3.0180 & 2.8659 & 3.1786 & 3.1185 & 4.4216 \\
\hline
\end{tabular}

Notes:

1. An HLN 'S' statistic greater than 1.47 indicates significant difference at $10 \%$ level; that greater than 1.65 indicates significant difference at $5 \%$ level; and that greater than 2.47 indicates significant difference at $1 \%$ level.

2. LM, long-memory model; RW, random walk model.

3. See Table I notes.

nearly unanimously. The HLN statistical test of equality between forecast mean square errors, in general, supports the findings that the long-memory model provides forecast performance superior to that of the random walk, especially at the longer forecast horizons.

Our study demonstrates the existence of significant long memory in the nominal exchange rates in five of the six currencies studied and that the long-memory model outperforms both the monetary structural models and the random walk model in short-run forecasting. This strongly suggests that the long-memory model be seriously studied in future work as an alternative to the monetary and/or random walk models.

\section{Acknowledgments}

We would like to thank the editor of Journal of Forecasting, Scott Fullwiler, John Geppert, Noor A. Ghazali, Kenneth Rebeck, and Hendrik van den Berg for many helpful comments on this paper. We particularly thank Fal- 
law Sowell for providing the Fortran program used in the analysis, Kermit Rose for computing assistance, and Gwendolyn Mitchell for editorial assistance. Any remaining shortcomings are, however, the responsibility of the authors. The first author is also a Professor of Statistics at Benedict College in Columbia, South Carolina.

\section{References}

Baille RT, Bollerslev T. 1994. The long memory of the forward premium. Journal of International Money and Finance 13: $565-571$.

Bilson JFO. 1978. Rational expectations and the exchange rate. In The Economics of Exchange Rates: Selected Studies, Frenkel JA, Johnson HG (eds). Addison-Wesley: Boston, MA.

Booth GG, Kaen FR, Koveos PE. 1982. R/S analysis of foreign exchange rates under two international monetary regimes. Journal of Monetary Economics 10: 407-415.

Cheung Y-W. 1993. Long memory in foreign-exchange rates. Journal of Business and Economic Statistics 11: 93-101.

Cheung Y-W, Lai KS. 1993. A fractional cointegration analysis of purchasing power parity. Journal of Business and Economic Statistics 11: 103-112.

Cheung Y-W, Lai KS. 1995. A search for long memory in international stock market returns. Journal of International Money and Finance 14: 597-615.

Cheung Y-W, Lai KS. 2001. Long memory and nonlinear mean reversion in Japanese yen-based real exchanges rates. Journal of International Money and Finance 20: 115-132.

Diebold FX, Rudebusch GD. 1989. Long memory and persistence in aggregate output. Journal of Monetary Economics 24: 189-209.

Diebold FX, Rudebusch GD. 1991a. Is consumption too smooth? Long memory an the Deaton paradox. Review of Economics and Statistics 73: 1-9.

Diebold FX, Rudebusch GD. 1991b. On the power of Dickey-Fuller tests against fractional alternatives. Economics Letters 35: 155-160.

Diebold FX, Husted S, Rush M. 1991. Real exchange rates under the gold standard. Journal of Political Economy 99: 1252-1271.

Dornbusch R. 1976. Expectations and exchange rate dynamics. Journal of Political Economy 84: 1161-1176.

Fox R, Taqqu MS. 1986. Large-sample properties of parameter estimates of strongly dependent stationary gaussian time series. Annals of Statistics 14: 517-532.

Frankel JA. 1979. On the mark: theory of floating exchange rates based on real interest rate differentials. American Economic Review 69: 1075-1082.

Frankel JA, Froot K. 1990. Chartists, fundamentalists, and the demand for dollars. In Private Behavior and Government Policy in Interdependent Economies, Courakis A, Taylor M (eds). Clarendon Press: Oxford; 73-126.

Frenkel JA. 1976. A monetary approach to the exchange rate: doctrinal aspects and empirical evidence. Scandinavian Journal of Economics 78: 200-224.

Geweke J, Porter-Hudak S. 1983. The estimation and application of long memory time series models. Journal of Time Series Analysis 4: 221-238.

Gil-Alana LA, Robinson PM. 2001. Testing of seasonal fractional integration in UK and Japanese consumption and income. Journal of Applied Econometrics 16: 95-114.

Granger CWJ. 1980. Long memory relationships and the aggregation of dynamic models. Journal of Econometrics 14: $227-238$.

Granger CWJ, Joyeux R. 1980. An introduction to long-memory time series models and fractional differencing. Journal of Time Series Analysis 1: 15-29. 
Harvey D, Leybourne S, Newbold P. 1977. Testing the equality of prediction mean squared errors. International Journal of Forecasting 13: 281-291.

Hassler U, Wolters J. 1995. long memory in inflation rates: international evidence. Journal of Business and Economic Statistics 13: 37-45.

Hooper P, Morton J. 1982. Fluctuations in the dollar: a model of nominal and real exchange rate determination. Journal of International Money and Finance 1: 39-56.

Hosking JRM. 1981. Fractional differencing. Biometrika 68: 165-176.

Kim BJC, Mo S. 1995. Cointegration and the long-run forecast of exchange rates. Economics Letters 48: 353-359.

Lo AW. 1991. Long-term memory in stock market prices. Econometrica 59: 1279-1313.

Meese RA. 1986. Testing for bubbles in exchange markets: the case of sparkling rates. Journal of Political Economy 94: 345-372.

Meese RA, Rogoff K. 1983a. Empirical exchange rate models of the seventies: do they fit out of sample? Journal of International Economics 14: 3-24.

Meese RA, Rogoff K. 1983b. The out-of-sample failure of empirical exchange rate models: sampling error or misspecification? In Exchange Rates and International Macroeconomics, Frenkel JA (ed.). University of Chicago Press: Chicago; 67-105.

Meese RA, Singleton KJ. 1982. On unit roots and the empirical modeling of exchange rates. Journal of Finance 37: 1029-1035.

Porter-Hudak S. 1990. An application of the seasonal fractionally differenced model to the monetary aggregates. Journal of the American Statistical Association 85: 338-344.

Robinson PM. 1994. Efficient tests of nonstationary hypotheses. Journal of the American Statistical Association 89: 1420-1437.

Schinasi GJ, Swamy PAVB. 1989. The out-of-sample forecasting performance of exchange rate models when coefficients are allowed to change. Journal of International Money and Finance 8: 375-390.

Smith J, Taylor N, Yadav S. 1997. Comparing the bias and misspecification in ARFIMA Models. Journal of Time Series Analysis 18: 507-528.

Sowell F. 1992. Maximum likelihood estimation of stationary univariate fractionally integrated time series models. Journal of Econometrics 53: 165-188.

Taylor MP, Allen H. 1992. The use of technical analysis in the foreign exchange market. Journal of International Money and Finance 11: 304-314.

West KD. 1987. A standard monetary model and the variability of the Deutschmark-dollar exchange rate. Journal of International Economics 23: 57-76.

Wolff CCP. 1987. Time-varying parameters and the out-of-sample forecasting performance of structural exchange rate models. Journal of Business and Economic Statistics 5: 87-97. 